\title{
Some Philosophical Musings on the RTSRE conference
}

\author{
David H McKinnon ${ }^{1 *}$
}

\begin{abstract}
This paper is written in response to an invitation after having had some discussions with the organizer, Dr Michael Fitzgerald. We had been discussing our reactions to all of the papers presented. I had been somewhat dismayed by the "lack of educational knowledge" displayed. Reflection revealed that this was not surprising given that so few had undertaken any advanced training in education. Many were scientists and experts in their fields of astronomy, technology or robotics. Consequently, I cover some key topics that I consider to be important in this domain. These include: the message systems of curriculum, pedagogy and evaluation in education; how these are typically operationalized; and, with this operationalization, how we encounter the problems made manifest during the conference. I offer some suggestions on how to overcome these.

${ }^{1}$ Edith Cowan Institute for Education Research, Edith Cowan University, Joondalup, WA, Australia

*Corresponding author: d.mckinnon@ecu.edu.au
\end{abstract}

\section{Introduction}

Michael Fitzgerald invited me to put some thoughts to paper on the RTSRE conference in San Diego. The first day was all about the technology. The second day was a mix of technology and education. The third day was mostly about education. The fourth day was built around student research projects.

My first reaction to the technology that was being showcased on the first day was one of: "I wish that it had been so easy for us back in the 1990s." That reaction was followed by "Oh My Gosh" and "So much is now possible". Consequently, I offer my congratulations to all. However, there was an undercurrent of unease that was punctuated by comments from Russ Gennet, and especially from Richard Berry who laid bare his experiences and frustrations with the two students and their search for the one right answer. Their desires contrasted with Richard's alternative search for a method, built on his flexibility, to achieve an alternative goal because conditions were not right for what he had initially planned. He asked something like: If anyone knows how to get to the teachers/students and keep them...I would like to know.

His question was left unfinished and indeed, unanswered. Others were not quite so brave to reveal their frustrations with the education system and with teachers and/or students. Indeed, I was given the initial impression that everything was working just fine. As the days unfolded, Berry's question came to the fore. Others were experiencing difficulties and not with the technology. Rather, the problems related in large part to the agents within the education system, whether they were teachers, students, administrators or the authorities.

There was another layer of frustration that also became clearer. This one related to the issue of the software tools and the different platforms on which they had to run: Apple computers with different operating systems, Windows computers with different operating systems, tablets with different operating systems of varying ages, etc. In short, the 
lack of a common technology standard across the education sector was a source of frustration.

On the Wednesday, largely the education day, we began to hear about the actual problems that educational researchers had encountered. Moreover, Slater alluded to many of these problems in his keynote address. We also heard from the Panel on the subject of educational evaluation and its importance in order to avoid, at least in part, confirmation bias.

The purpose of this paper is thus threefold. First, I will address the issue of the systemic problem common to all education systems. Second, I will address the need for cooperation across the technological, scientific and educational domains. Finally, I will address the need to share what we find. In doing so, my assumption is that remote and robotic telescopes can do "good things" not only for science education in particular but also for other curriculum domains more generally as well as for the students and their teachers.

\section{The Systemic Problem}

I define this problem as one which occurs at all levels: in elementary, secondary and tertiary settings. However, there are different emphases at each level. The system imposes major constraints on what teachers in elementary and secondary settings can and cannot do. It is mostly driven by accountability. The teachers are accountable for what they do in their classrooms. They are accountable for the outcomes that their students achieve. They are accountable to Teacher Registration Boards for their treatment of the curriculum elements that they are supposed to teach. The system imposes a timetable of events that occur during any teaching day. The system dictates how much time is to be spent on each curriculum domain. The system dictates the form of assessment and evaluation that has to happen and which the society uses to make judgments not only about the student but also about the teacher, the school, the district, and the system itself. The system also dictates that all of the assessment information about student outcomes has to be made public.

One might ask what is the purpose of education? Different philosophers of education have addressed this question over the past 60 years. R. S. Peters (1973) expressed it in a way that most took my fancy when I read his book in the early 1990s: The purpose of education is to improve the human condition. That is a big ask, but it can be deconstructed into a number of paths that help the individuals in our classrooms. Some are instrumental such as helping them to get a good job. Others are more personal such as to make the learning experience more enjoyable so that they go on learning. However, there are many barriers to achieving this laudable purpose and also many issues that have to be addressed.

Bernstein $(1971 ; 1975)$ addressed many of the issues in his analysis of education. He takes the particular standpoint that education is designed as the society's means by which it can ensure its future. In so doing, education is constructed with underlying "message systems" that are the means by which the society's messages are conveyed to its clients, the students. He defines three message systems. These are: curriculum, pedagogy and evaluation (Berstein, 1975). The way in which these systems are constructed conveys explicit messages to its clients, our students.

Thus, curriculum can exist on a continuum at one end of which Bernstein describes its operation as collection code of curriculum organisation (Berstein, 1975). That is to say, the curriculum is made up of a collection of "subjects" that stand in isolation from each other and where the barriers between them are strong. There are the usual subjects that we all recognize: Physics, Chemistry, Biology, Mathematics, English, French, Italian, Latin, Art, Technology etc. A "curriculum" is designed for each. Woe betide anyone who tries to bring English into Physics: the English teachers complain that their subject is being compromised.

At the opposite end of the curriculum continuum is the integrated code where there are no "subjects" per se. Knowledge, after all, is knowledge. In the 
integrated code, there are problems, projects and/or themes of various kinds that can be addressed within the educational setting in which different knowledge domains are brought to bear at different times and in different depths in order to address the needs of the problem/project/theme being considered or taught. To be a little more explicit through an example that I have experienced, consider the problem of managing a national park. The park is beset by a variety of pressures such as animals, wildlife, land use, water, and the people who wish to access its resources such as visitors for leisure, miners for the mineral resources and water, graziers for access to the land on which their domesticated animals can find food and water. A thematic approach to the problem of managing the competing demands makes good sense since the different sources of pressure require an understanding of the ecosystems within the park (botany, biology, geology, hydrology); data will need to be collected, treated, and analyzed (mathematics and statistics) and reports created for the various audiences (English, sociology) that are cognizant of the best way to communicate the information to the wider society.

Bernstein also argues that the form the curriculum takes sends powerful messages, through its construction, to the students who experience it. Physics, Latin and Mathematics are difficult subjects and thus possess high status within the society. Art and woodwork are low status subjects. Anyone can draw, can't they? But only the brightest can do the difficult subjects.

The second message system is Pedagogy. That is to say, the way in which we teach also sends messages to the students. "I am teacher. Your job is to learn." or "I taught it. You did not learn it." In other words, they have to remember it for the test or examination. When the teacher talks, all should be listening. Here, the teacher is in the more powerful position compared with the students. Nonetheless, the teacher has to obey the departmental head, the vice principal, the principal, the school board, the education department, the Minister for Education. This hierarchy is obvious.
This pedagogical frame, based on power, is described as an instructionist frame. Each level instructs the next one down. There is a body of knowledge "out there" that has to be instilled (taught) into the brains of the students.

In contrast to this form of pedagogy is one that exists within a constructivist frame where all people learn together while interacting with each other (Vygotsky and Cole (1978); Von Glasersfeld (1991)). Knowledge does not exist outside of the brain of a cognizing being. Each being has to make or remake that knowledge for him/herself to make it their own. In other words, they have to understand it in order to learn it. In this frame, power matters much less. Rather, power comes to be vested in those who have the best ideas. Power is fluid because next week, it might be someone else who has all the good ideas in relation to a different problem. Bernstein $(1975,2000)$ thus argues that the form the pedagogy takes sends powerful messages about where the learner is situated in the power structure.

The final message system of Evaluation with its two attendant sub-domains of Assessment and Measurement is designed to work out how much an individual "knows". Like the other two message systems, evaluation can exist on a continuum from the Norm-Referenced one, with which we are most familiar, to the Criterion Referenced one at the other end. Teachers normally have less experience with this latter form.

The Norm-Referenced method is designed to tell the society where a student is ranked in the pecking order. The society pays great attention to the results of such assessment results and evaluates how the student, the school, the school district, the state compares with other students, schools etc. This form of assessment sends messages to the student, on the basis of their performance, about that to which they might aspire when they leave school/university. Putting this "value" on the assessment outcomes is the evaluation or judgment that society and its members make of the individual learner etc.

Criterion-Referenced assessment tells the society 
what the student can do and perhaps how well they can do it. It does not compare them with other students. We are less familiar with this form of assessment in schools given the preponderance of norm referenced forms like SAT scores, Higher School Certificate results, Tertiary Entrance Ranks etc., but it nonetheless pervades our society. Would you travel on an airplane where the pilot can only safely land $50 \%$ of the time, or go to a doctor who only successfully treats $50 \%$ of her/his patients? This 50\% "pass mark" is widespread in education and an artifact of the norm-referenced system. Mastery is something that we value but which the society does not recognize when it evaluates the products of schooling.

\section{The Tertiary Sector}

Colleges and universities are somewhat different to schools. Professors have a much greater degree of autonomy over the construction of their curriculum, the teaching methods they employ, and the forms of assessment they use, although I would add that I have observed and experienced many woeful professors. Nonetheless, they may have to justify these only to their departmental heads. Moreover, in the first year of college, the dominant construction of the three message systems is similar to that practiced in schools.

However, as the college students demonstrate their commitments and capacities, the message systems change to become more integrated, constructivist, and criterion-referenced. For example, some third and fourth year students, who have demonstrated their capacity, are invited by their professors to come to morning coffee. There, the students experience the constructivist arguments being forcefully put by the protagonists, their professors, and approaches constructed/defined that can be explored by their students with the final report (thesis) being judged on its merits of what it takes to be a good physics/chemistry/astronomy/etc. researcher. That is to say, the curriculum has moved to become an integrated code, the pedagogy to become constructivist, and the form of assessment criterion-referenced.

\section{Mode of Production, Social Formation, and Structure of Schooling}

One might ask the question of why schools have their message systems structured in the ways described above. I would assert that both elementary and secondary education in Western industrial societies have evolved along lines quite different from the educational concepts and provisions that appear to be required for contemporary and future technological society. Contemporary educational systems developed in response to the imperatives of the industrial mode of production (e.g., Bowles et al., 1976; Bowles and Gintis, 1986). This is not to say that that the mode of production determines the form and content of education in any strict deterministic fashion (e.g., Apple, 1988) but rather, there are parallels between the social relations of production in the workplace and the social relations of learning in schools. While there is no simple one-to-one correspondence between the economics, the culture and the social relations found in schools, the parallels can be striking (Apple, 1988; Liston, 1988). Table 1 illustrates the parallelism.

One might ask the following question: why are Western societies still continuing to structure schooling for an industrial mode of production when we have now moved well beyond that employment domain to one that requires innovation in a society where access to information is but a few finger taps away on a computer or a mobile device? I would maintain that that is what we are concerned about in RTSRE and the problem articulated by Richard Berry is an articulation of the disjunct between our post-industrial modes of production and the industrial mode still largely practiced in schools.

\section{Philosophical Musings on RTSRE}

With that little background on the three Message Systems and structural parallelism, I now set out to interpret what many presenters appeared to desire as outcomes of what they were doing with robotic 


\begin{tabular}{|c|c|}
\hline Mode of Production Embodies: & Structure of Schooling: \\
\hline $\begin{array}{l}\text { An external source of control over work and } \\
\text { conditions of work; }\end{array}$ & $\begin{array}{l}\text { Placing control over the learning process with the } \\
\text { teacher and not the student; }\end{array}$ \\
\hline $\begin{array}{l}\text { Fragmentation of the productive process with a } \\
\text { social and technical division of labor; }\end{array}$ & $\begin{array}{l}\text { Fragmentation of the learning process socially } \\
\text { through streaming and technically through } \\
\text { compartmentalization of school subjects; }\end{array}$ \\
\hline $\begin{array}{l}\text { Extrinsic reward for work in the form of wages } \\
\text { and bonuses; }\end{array}$ & $\begin{array}{l}\text { Extrinsic rewards for work and achievement in } \\
\text { the form of marks, grades, certificates, position in } \\
\text { class, prizes and teacher approval; }\end{array}$ \\
\hline $\begin{array}{l}\text { An uneven reward structure based on } \\
\text { competitive rather than cooperative principles; }\end{array}$ & $\begin{array}{l}\text { An uneven reward structure based on } \\
\text { competition rather than cooperation in which } \\
\text { success for some means failure for others and } \\
\text { where cooperation is often regarded as cheating; }\end{array}$ \\
\hline $\begin{array}{l}\text { Submissiveness and conformity required by a } \\
\text { typically authoritarian organization of work and } \\
\text { an acceptance of a secondary role for human } \\
\text { labor which is being replaced by machines; }\end{array}$ & $\begin{array}{l}\text { Rule conformity is highly valued as the normative } \\
\text { basis of learning and schoolwork; }\end{array}$ \\
\hline $\begin{array}{l}\text { A hierarchically organised workplace based on } \\
\text { chains of command, authority, expertise and } \\
\text { status. }\end{array}$ & $\begin{array}{l}\text { Hierarchic school organisation characterised by } \\
\text { superordinate/subordinate relations between } \\
\text { teachers and students, administrators and } \\
\text { teachers and between high status and low status } \\
\text { subjects. }\end{array}$ \\
\hline (Apple, 1988) & (Liston, 1988) \\
\hline
\end{tabular}

Table 1: Mode of Production, Social Formation and the Structure of Schooling

telescopes in schools. I again take Richard Berry as the example. He had a "curriculum" in mind when he set out to observe "things" at the observatory with the students and of which they were aware. However, conditions did not suit his plan. He changed that plan and introduced other investigations. This is more of an integrated code rather than of a collection-code curriculum. If he had adhered to the latter, he would have said words to the effect that they could not do "what has to be done" and would have retired to a warm bed for the remainder of the night. This form of flexibility is embedded within the integrated code. One never knows where the investigation will take the researcher/students: flexibility is not only demanded, it is a natural way to proceed. However, the students were more concerned about what they had set out to do. They were not flexible. They had been socialised into "this is what you need to learn" domain and not the "what can we find out".

Richard's evaluation system was also at the other end of the spectrum from that of the students, who were concerned only about getting "the right answer". Richard was more concerned that the students would be flexible enough to experiment in light of the new project and tried to get them to talk through the methods. Indeed, he described how he talked though what he was doing, how he was thinking. This talking/interaction is at the heart of a constructivist pedagogy. In contrast, the students wanted to be told what to do, a feature of instructivist pedagogy where the power rests with the teacher and not with the student. He tried to engage them in making the method and in experimenting with it to see what happened. All the while, he was talking with them, and not at 
them. There were no "right answers" that Richard could give the students: indeed, there was no right answer.

I would conclude that the approach from diametrically opposed ends of the three message systems spectra was on a hiding to very little, if not nothing. Indeed, one of the two students fell asleep on the observatory floor thus disengaging from what was happening. I ask myself if this outcome was any surprise. Unfortunately, the answer is "No". Schools socialise students in ways that are profoundly different from the ways that scientists expect to behave: collaboratively (in schools, that is called cheating); problem-solving as they go (in schools, such a lesson is judged to be a disaster you have to get the right answer); making things from what is lying around or commission new equipment (that never/seldom happens in schools or is described as bad preparation by the class); arguing with each other to make sense of what is happening (good classrooms are quiet classrooms) etc.

I concluded many years ago that the message systems of the RTSRE domain are constructed differently from those extant in our respective education systems. We should all recognise this as a problem to be overcome and not an impenetrable barrier. Such a threat to the use of robotic telescope systems can be turned into an opportunity to become a strength for our various enterprises. I would also add here that if we go into schools to present science teachers with access to our wonderful equipment and ideas for student research projects, there may be a polite response from some or many and no action, while the enthusiastic early adopters jump in boots and all. Yet it will likely be accompanied by a deafening silence and paucity of activity from the vast majority. Richard and Russ asked the question of us educators: What must I do to get them (teachers and students) involved?

So, what follows is some insights built around the disjunct of the respective message systems. Each is unpacked a little to make explicit what teachers might expect to see versus what you have implicitly, not explicitly, embedded. I will also illustrate some of these issues by providing brief examples from our own experiences in the research we have conducted over the past 20 years. I also provide references to the seminal authors in the educational domain whose work we have used with success. I also add that if you want to communicate with me, please do so.

\section{Curriculum}

1. All of the instructional/inquiry/project materials have to be very well prepared. Indeed, they have to be so good that the teacher has nothing to do to implement them other than a little bit of homework.

This is a deep form of professional learning for the teacher. The teacher has to do the teaching and thus be prepared. This stands in contrast to normal professional development where they are told what to do and expected to then go and do it (Collection Code Curriculum, Instructivist Pedagogy).

Yet, we have to structure the materials in such a way that we subvert the curriculum message system. Inevitably, it will also involve subverting the other two message systems. Thus, the subversion comes from embedding the integrated mode within what is apparently a collection code curriculum. The materials have to be constructed in such a way that you are telling them what to, do i.e., the pedagogy appears to be instructivist. It is almost like them having to follow a recipe. However, there are embedded suggestions about how the teacher might manage the exercise or experiment. An example follows.

\section{Example}

I set my elementary teacher-education students a variety of investigations in a subject largely focused on Astronomy (McKinnon et al., 2017). By week four of the semester, the cooperative group (usually 4) assigns each member two projects about the Solar System to teach to the rest of them. They schedule these projects in a logical fashion and when they teach theirs to their group the other members provide feedback on how well it was done from a variety of educational perspectives. 
One such project relates to the physical properties of the planets with a suggestion that a PowerPoint might be useful. Often, and I mean often, the responsible student goes off and creates an enormous slideshow with multiple slides on each planet illustrated with images and lots of figures related to size, mass, number of moons etc. When it is their turn to teach, the student "teaches it" and receives lots of criticism from her/his peers about being "talked at" (Instructivist Pedagogy). So, after 13 years of schooling, they are saying to each other "I hate being talked at just like at school".

My question of the student with the others listening in: How much work did you have to do to create all of that? Answer: Lots and lots. Next question: Why not use a cooperative learning approach (Jigsaw and Jigsaw II) where you prepare two exemplars, and then give the others this as a template for each one to find the information for just two planets (i.e., $2+3 \times 2=8$ planets) (the Jigsaw part - divide the task up)? Then, each presents to the other members of the group what they have found for their two planets (the Jigsaw II component)?

In the process they understand the value of cooperative learning strategies where they empower the students to do their own research as part of a bigger task and also teach the others about what they have found. In the process, one has subverted the collection code through a set of cooperative learning strategies with an inbuilt criterion-referenced assessment approach when they present their data to the rest. When seen in operation, the elementary teachers in schools think that it is wonderful.

2. The materials cannot be "in addition to" what the teacher normally does. Otherwise, the teacher will not do them. The teacher does not have the curriculum time to do the extra material. Time is tight enough as it is.

The materials have to be structured in such a way that they replace something that a teacher already does from a collection code perspective, viz., This unit is about "light" so we do the Inverse Square Law. In our astronomy unit, we use that formula (with Logarithms!) for apparent and absolute magnitudes to calculate distances.

Why not combine them in your unit? We do in Our Solar Siblings. The students come to deeply understand the formula with their conceptual understanding generated by the Inverse Square Law experiment/investigation and we develop an understanding of the mathematics behind the magnitude system through a scaffolded (Vygotsky and Cole, 1978) approach to work out brightness differences from magnitudes, the definition of magnitude and that magic number of $2.512 \ldots$ (the fifth root of 100). That is to say, we explicitly bring them into the Zone of Proximal Development (Vygotsky and Cole, 1978).

\section{Pedagogy}

3. The materials have to have embedded within them, all of the constructivist pedagogy suggestions.

An example might be to suggest that this activity might be best done in small groups with roles defined for the cooperative group-work (recorder, materials manager, reporter, manager, etc.). Or, consider the cooperative learning strategies alluded to in the example above where everyone does a portion that contributes to the whole rather than each student having to do the entire task on their own.

\section{Example}

When we do star cluster photometry, we divide an image of a cluster into regions of approximately equal numbers of stars. Each small group of three is assigned an area of the image and each member of the group a roll: recorder, map maintainer and aperture photometry person. The map maintainer writes a number beside the star that has just been measured while the recorder enters the brightness count into a spreadsheet. Each group does 10-15 stars in $\mathrm{U}, \mathrm{V}, \mathrm{B}, \mathrm{R}$ and I. These data are then uploaded to a Google Spreadsheet for all to download when the groups have finished. We can 
get a Color Magnitude Diagram in much less than 40 minutes containing the brightness counts for 80-120 stars in five filters. This cooperative learning strategy is called Jigsaw. Divide the task up. Let each group contribute to the big data generation task. In the professional learning approach, the teachers do it this way too. Thus, we model for them the cooperative learning strategies.

\section{Evaluation/Assessment}

4. The evaluation system should appear to be "norm referenced" while actually being "criterion referenced".

In all of the papers that I could attend at the RTSRE (most, apart from the parallel sessions), I took the deepest interest in those presenters who appeared to be frustrated with this aspect of assessment. That is to say, some, or many, students that were involved in presenters' projects wanted to know the answer and if they discovered something, was it the right answer. While Richard Berry's common response was "I don't know", the students' question is a clear signal that the school(s) they attended place emphasis on the norm-referenced Evaluation message system. It sends clear messages to students about what is valued: right answers. Yet we know how error prone most of astronomy is. So how does one re-educate the student. Here is a suggestion.

In our work, the students are developing skills. We need to make the skills explicit for the students as well as for the teachers. Instead of sitting a "skills test", students are required to apply their skills to, what for them is, a novel problem. We follow a path that involves Backward-Faded Scaffolding (Slater et al., 2008) where the teacher's role, and the determinism of the method fade in a structured fashion leaving the student as the researcher.

The first step involves Confirmatory Inquiry where the students in collaborative groups learn how to do "everything" by the teacher modeling all of the processes: ask the question, define and learn the method, learn how to present and interpret results, and how to present their conclusions. We apply this to measuring the distance to a well-known open cluster of stars. They usually get the "right answer" but there are minor variations amongst groups as they try to fit the Main Sequence to the scatter plot the class has generated. This provides us with an excellent opportunity to discuss errors and the impossibility of "exact right answers". They are in that Zone of Proximal Development (Vygotsky and Cole, 1978).

We then introduce another cluster that is heavily reddened although, they do not know this yet. They now know the approach defined in the confirmatory inquiry example. They know the Method, they apply it to the new cluster. A CMD is generated quite rapidly. Then we introduce the concept of reddening through experiment and they qualitatively evaluate the color of light passing through a liquid with their eyes and more quantitatively using a small hand-held spectrometer. This form of "structured inquiry" then allows them to take account of the reddening and derive a new distance for the cluster based on an analysis of their data using Color-Color Diagrams to derive an estimate of the color excess. This then allows them to calculate a better distance for the cluster taking the reddening into account.

The third form, Guided Inquiry, using the same cluster, also uses their brightness data to estimate the size of the cluster together with isochrone fitting being introduced at this stage to refine their age and distance estimates. The final stage of open inquiry taken by some students is to choose a cluster that has not been investigated, or whose data were generated in the early days of photographs or photo-multiplier tubes, and to fully analyze it. Their results are checked and an invitation extended to cooperate to write it up for publication (e.g., Fitzgerald et al., 2015).

In this frame, the assessment and evaluation system is Criterion Referenced with regards to the methodology, presentation, and referee feedback from the journal. The reward: a publication in a professional journal or presentation at a professional conference. 


\section{Conclusion}

My conclusions with respect to this brief reflection on what transpired over four days in San Diego, will, I hope, motivate more of you to go to the literature. Many of the answers are there although, unfortunately, they are not all in the same place. A group of us are attempting to do just that in the astronomy domain in the iSTAR database (http://istardb.org/) where you will find, and can contribute to, a growing collection of all articles, research papers and theses related to astronomy education (Slater et al., 2016). I hope that this resource will be used in ways that help prevent us from repeating the same mistakes that many have overcome and about which they have written in their dissertations, theses, and research publications.

If you too are concerned, as Jerome Bruner (1966) was, with having the student leap the barrier from learning to thinking, then the research projects that were delivered at our conference will require adjustments to Bernstein's message systems extant in today's education systems to make them less like the collection code, instructivist, norm-referenced ones that focus on the rewards of memorization and reproduction evident in our schools. Rather, they will have to be subvert these systems in order to move the teachers and their students to ones that require integrative thinking, constructivist collaboration and criterion-referenced assessment devices. These have a much higher probability of helping the student, and the teacher, make the leap we all desire to ready them for the emergent mode of production based on information and innovation.

\section{Acknowledgements}

I acknowledge the presenters at the Robotic Telescopes and Student Research in Education Conference in San Diego. I especially thank Richard Berry for agreeing to have his presentation, together with his frank comments, used as an example in this paper. Richard, I thank you for your frankness. Let there be more of it!

\section{References}

Apple, M. W. (1988). Social crisis and curriculum accords. Educational Theory, 38(2):191-201.

Bernstein, B. (1971). Class, codes and control. Vol. 1. Theoretical studies tow a sociology of language.

Bernstein, B. B. (2000). Pedagogy, symbolic control, and identity: Theory, research, critique. Number 4. Rowman \& Littlefield.

Berstein, B. (1975). Class, Codes and Control, vol. 3. Towards a Theory of Educational Transmissions.

Bowles, S. and Gintis, H. (1986). Democracy and Capitalism: Property. New York: Basic Books.

Bowles, S., Gintis, H., et al. (1976). Schooling in capitalist America, volume 57. New York: Basic Books.

Bruner, J. S. (1966). Toward a theory of instruction, volume 59. Harvard University Press.

Fitzgerald, M. T., Inwood, L., McKinnon, D. H., Dias, W., Sacchi, M., Scott, B., Zolinski, M., Danaia, L., and Edwards, R. (2015). Photometric and proper motion study of the neglected open cluster NGC 2215. The Astronomical Journal, 149(6):190.

Liston, D. P. (1988). Capitalist schools: Explanation and ethics in radical studies of schooling.

McKinnon, D. H., Danaia, L., and Deehan, J. (2017). The design of preservice primary teacher education science subjects: The emergence of an interactive educational design model. Journal of Astronomy and Earth Sciences Education, 4(1):1.

Peters, R. S., Tesar, M., and Locke, K. (1973). The philosophy of education. Oxford University Press Oxford.

Slater, S. J., Slater, T. F., and Shaner, A. (2008). Impact of backwards faded scaffolding in an astronomy course for pre-service elementary teachers 
based on inquiry. Journal of Geoscience Education, 56(5):408-416.

Slater, S. J., Tatge, C. B., Bretones, P. S., Slater, T. F., Schleigh, S. P., McKinnon, D., and Heyer, I. (2016). iSTAR First light: Characterizing astronomy education research dissertations in the iSTAR database. Journal of Astronomy and Earth Sciences Education, 3(2):125.

Von Glasersfeld, E. (1991). An exposition of constructivism: Why some like it radical. In Facets of systems science, pages 229-238. Springer.

Vygotsky, L. and Cole, M. (1978). Mind in Society: Development of Higher Psychological Processes. Harvard University Press. 